\title{
Qualidade microbiológica de carne bovina comercializada na forma de bife*
}

\section{Microbiological quality of beef marketed in steak form}

\author{
Karoline Mikaelle de Paiva Soares, ${ }^{* *}$ Jean Berg Alves da Silva, ${ }^{* *}$ Lara Barbosa de Souza, ${ }^{* * *}$ Carolina Gouveia de Mendes, ${ }^{* * *}$ \\ Maria Rociene Abrantes, ${ }^{* * *}$ Maria Carla da Silva Campelo, ${ }^{* * *}$ Amanda Sabino de Souza***
}

\begin{abstract}
Resumo
O presente estudo teve por objetivo avaliar a qualidade microbiológica de bifes de carne bovina. Para tanto, 60 amostras de bifes de carne bovina foram coletadas, em diferentes estabelecimentos comerciais localizados em oito diferentes municípios no estado do Rio Grande do Norte, e transportadas em caixas isotérmicas, ao Laboratório de Inspeção de Produtos de Origem Animal da UFERSA. Foram realizadas análises microbiológicas para a contagem de micro-organismos aeróbios mesófilos e psicrotróficos, contagem de Staphylococcus sp., determinação do número mais provável de coliformes totais e termotolerantes, além da pesquisa de Salmonella ssp. A contagem de aeróbios mesófilos variou de 4,85 a > 7,40 $\log _{10} \mathrm{UFC/g}$. Na análise de psicrotróficos, 50 amostras obtiveram contagens superiores a 7,4 $\log _{10} \mathrm{UFC} / \mathrm{g}$. A contagem de Staphyloccocus sp. foi superior a 3 log $\mathrm{l}_{10} \mathrm{UFC} / \mathrm{g}$ em $77 \%$ das amostras. A maioria das amostras apresentou número mais provável de coliformes totais e termotolerantes elevado. A presença de Salmonella ssp. foi detectada em amostras de cinco estabelecimentos. Assim, verificou-se que os bifes avaliados apresentaram baixa qualidade microbiológica, podendo representar riscos à saúde do consumidor.
\end{abstract}

Palavras-chave: contaminação, riscos microbiológicos, Salmonella ssp., Staphylococcus sp.

\begin{abstract}
This study aimed to evaluate the microbiological quality of beef steaks. Therefore, 60 samples of beef steaks were collected in different outlets located in eight different municipalities in the state of Rio Grande do Norte, and transported in cool boxes, the Inspection Laboratory Animal Origin of UFERSA products. Were analyzed for microbiological for the count of aerobic mesophilic microorganisms and pscicrotróficos, Staphylococcus sp count., Determining the most probable number of total and fecal coliforms, besides the research of Salmonella ssp. The mesophilic aerobic counts ranged from 4,84 to $>7,40 \mathrm{log}_{10} \mathrm{CFU} / \mathrm{g}$. In psychrotrophic analysis, 50 samples had counts exceeding $7,40 \log _{10} \mathrm{CFU} / \mathrm{g}$. The count of Staphylococcus sp. was greater than 3 log ${ }_{10} \mathrm{CFU} / \mathrm{g}$ in $77 \%$ of samples. Most samples showed most probable number of coliforms and thermotolerant high. The presence of Salmonella ssp. was detected in five samples establishments. Thus, it was found that the evaluated steaks showed low microbiological quality and can pose risks to consumer health.
\end{abstract}

Keywords: contamination, microbiological risks, Salmonella ssp., Staphylococcus sp.

\section{Introdução}

A qualidade de carnes é um termo amplo e complexo que pode ser definido como uma combinação de características que respondem pelo produto como um todo (Ramos e Gomide, 2012). As características intrínsecas da carne, como a elevada atividade de água, $\mathrm{pH}$ próximo à neutralidade e elevado teor de nutrientes, a torna um alimento altamente susceptível ao crescimento de micro-organismos (Ordonez, 2005). A presença de micro-organismos deteriorantes em carnes é inevitável, podendo-se controlar o seu número, enquanto os patogênicos devem ser evitados (Castillo, 2006).

A carne bovina pode ser facilmente contaminada por microorganismos. A sua manipulação durante o processamento pode representar um aumento nas contagens de deteriorantes, além de representar um risco para contaminação por patógenos como a Samonella e o Staphylococcus aureus. Entre os micro-organismos deteriorantes de importância em carnes refrigeradas, destacam-se os psicrotróficos pela capacidade de sobrevivência e atividade mesmo em temperaturas de refrigeração, independentemente da sua temperatura ótima de crescimento (Jay, 2005; Castillo, 2006; Forsythe, 2013). Não existe uma legislação específica que contemple padrões para bactérias deteriorantes em carnes bovinas in natura resfriadas. A RDC N ${ }^{\circ} 12$ de 2 de janeiro de 2001 (Anvisa, 2001) preconiza como requisito microbiológico único para carnes bovinas frescas a ausência de Salmonella em $25 \mathrm{~g}$.

Nos últimos anos, observa-se o aumento no consumo de carnes bovinas comercializadas na forma de bifes, que são comercializados em embalagens individuais pré-preparadas, o que torna estes alimentos mais práticos e convenientes por serem ofertados cortados e porcionados, o que facilita o seu preparo (Santos e Oliveira, 2012).

\footnotetext{
*Recebido em 9 de dezembro de 2014 e aceito em 20 de setembro de 2015.

**Departamento de Ciências Animais, Universidade Federal Rural do Semi-Árido Mossoró, RN.

***Programa de Pós-Graduação em Ciência Animal, Universidade Federal Rural do Semi-Árido, Mossoró, RN.

****Discente do curso de Biotecnologia, Universidade Federal Rural do Semi-Árido Mossoró, RN.

Autor para correspondência: karolinesoares@ufersa.edu.br.
} 
Várias pesquisas têm sido realizadas para avaliar a qualidade de microbiológica de carne bovina in natura moída, que também é intensamente manipulada, sem o posterior uso de métodos de conservação em conjunto com a refrigeração (Leite Júnior et al., 2013; Abreu et al., 2011; Oliveira et al., 2008; Motta et al., 2000; Silva et al., 2004). Em contrapartida, poucos estudos têm reportado a qualidade microbiológica de bifes de carne bovina in natura. Neste contexto, o objetivo do presente estudo foi avaliar a qualidade microbiológica de bifes de carne bovina resfriados comercializados no Rio Grande do Norte.

\section{Material e métodos}

Foram coletados bifes de coxão mole bovino provenientes de diferentes estabelecimentos comerciais localizados em oito cidades do estado do Rio Grande do Norte.

As coletas ocorreram em outubro de 2013 em supermercados, frigoríficos e casas de carne dos municípios de Natal (10), Mossoró (10), Parnamirim (10), Pau dos Ferros (8), Assu (8), Apodi (8), Lajes (3) e Itaú (3).

Os bifes foram escolhidos ao acaso, em estabelecimentos que ofertavam carnes pré-cortadas na forma de bifes embalados em bandejas de poliestireno expandido envoltas por filmes de policloreto de vinila, e armazenadas sob condições de refrigeração.

Após a coleta, as amostras foram acondicionadas em caixas isotérmicas, com gelo, e transportadas imediatamente ao Laboratório de Inspeção de Alimentos de Origem Animal, do Departamento de Ciências Animais da Universidade Federal Rural do Semiárido, onde as mesmas foram submetidas a análises de $\mathrm{pH}$ e análises microbiológicas.

A qualidade microbiológica dos bifes foi determinada através das seguintes análises: contagem de micro-organismos aeróbios mesófilos, psicrotróficos, Staphylococcus sp.; pesquisa de Salmonella sp. e determinação do número mais provável de coliformes totais e termotolerantes, além da análise do potencial hidrogeniônico $(\mathrm{pH})$.

$\mathrm{O}$ pH foi medido através de aferição direta no alimento utilizandose um potenciômetro digital, normalizado com tampões padrão a 4 e 7 (Instituto Adolfo Lutz, 2008).

As análises microbiológicas foram realizadas no Laboratório de Inspeção de Produtos de Origem Animal da UFERSA, de forma asséptica.

Utilizou-se a metodologia proposta pela Instrução Normativa $\mathrm{N}^{\circ}$ 62/2003 do Ministério da Agricultura, Pecuária e Abastecimento (MAPA).

Inicialmente pesou-se, em balança analítica de precisão, $25 \mathrm{~g}$ de bife, diluindo-se em $225 \mathrm{~mL}$ de Solução Salina Peptonada Tamponada a 0,1\% (Brasil, 2003).Através de um Stomacher, realizou-se a homogeneização do conteúdo durante 2 minutos, o que resultou na diluição de $10^{-1}$, e, a partir desta, realizaram-se as diluições subsequentes, pipetando-se $1 \mathrm{~mL}$ de cada diluição em tubos do tipo de ensaio contendo $9 \mathrm{~mL}$ de Solução Salina Peptonada Tamponada a 0,1\%, com a homogeneização dos tubos auxiliadas pelo uso de vórtex (Brasil, 2003).

Para a contagem de micro-organismos aeróbios mesófilos, utilizaram-se placas de Petri previamente esterilizadas e identificadas, cada amostra foi analisada em duplicata. Semeou- se $1 \mathrm{~mL}$ de cada diluição, separadamente, em 15 a $20 \mathrm{~mL}$ de Ágar Padrão para a semeadura em profundidade. Após o endurecimento do meio, as placas foram incubadas invertidas em estufa bacteriológica, à temperatura de $37^{\circ} \mathrm{C}$, durante 48 horas. A leitura foi realizada nas placas, utilizando-se um contador de colônias, em placas que apresentavam entre 25 e 250 colônias (Brasil, 2003).

$\mathrm{Na}$ contagem de micro-organismos psicrotróficos, utilizou-se método semelhante ao anterior, porém com diferenças quanto à temperatura e tempo de incubação que neste caso foram respectivamente: $7^{\circ} \mathrm{C} \pm 1^{\circ} \mathrm{C}$ e sete dias (Brasil, 2003).

A contagem de Staphylococcus sp. foi realizada através da semeadura em Ágar Baird Parker, suplementado com solução de gema de ovo e telurito. As placas foram incubadas à temperatura de $37^{\circ} \mathrm{C}$, durante 48 horas. Realizaram-se as contagens das colônias típicas e não típicas nas placas que continham entre 20 e 200 colônias, com auxílio de um contador de colônias (Brasil, 2003).

O número mais provável de coliformes totais foi determinado utilizando-se tubos de ensaio, estéreis, contendo Caldo Lauryl Sulfato, verificando-se a presença ou ausência de formação de gás nos tubos de Duhran. Os tubos de ensaio foram mantidos em banho-maria em prova presuntiva a $37^{\circ} \mathrm{C}$, durante 48 horas (Brasil, 2003).

Os tubos positivos foram repicados através de alça de platina, em caldo verde-brilhante, durante 48 horas a $37^{\circ} \mathrm{C}$, para confirmar a sobrevivência de coliformes totais. Por último, os tubos positivos foram transferidos para Caldo Escherichia coli (EC), permanecendo em banho-maria a $45^{\circ} \mathrm{C}$ durante 48 horas para determinação de NMP de coliformes termotolerantes. A positividade ou não das amostras para coliformes termotolerantes foi detectada através da presença ou ausência de formação de gás no interior dos tubos de Duhran. Os resultados foram expressos em NMP por grama (Brasil, 2003).

Na pesquisa de Samonella spp, $25 \mathrm{~g}$ de cada amostra foi diluída em $225 \mathrm{~mL}$ de Solução Salina Peptonada. Este conteúdo foi incubado em estufa bacteriológica por 16 a 20 horas a $36 \pm 1^{\circ} \mathrm{C}$. Este procedimento foi realizado para pré-enriquecer a amostra. Em seguida, procedeu-se com a etapa de enriquecimento utilizando-se caldos seletivos para a Salmonella spp. Realizouse a diluição de 0,$1 ; 1$ e $1 \mathrm{~mL}$, respectivamente em $10 \mathrm{~mL}$ de caldos Rappaport Vassiliadis, tetrationato e selenito cistina, com posterior incubação em banho-maria a $41 \pm 0,5^{\circ} \mathrm{C}$. Após 24 horas, semeou-se o conteúdo de cada caldo, com auxílio de alça de platina, realizando-se estrias para obtenção de colônias isoladas em placas de Petri contendo os meios sólidos seletivos Eosina Azul de Metileno e Ágar Salmonella Shigella. As placas foram incubadas invertidas $36 \pm 1^{\circ} \mathrm{C}$ durante 24 horas. Após o isolamento, a suspeita da presença Salmonella spp. foi investigada através das seguintes provas bioquímicas: reação em Agar TSI, presença de lisina descarboxilase e prova da urease (Brasil, 2003).

\section{Resultados e discussão}

Detectou-se Salmonella spp. em cinco (8,3\%) amostras de bifes analisadas no presente estudo. Em carnes provenientes dos municípios de Mossoró, Assu, Pau dos Ferros e Itaú, observouse a ausência de Salmonella spp. Na cidade de Parnamirim, 
amostras de dois estabelecimentos estavam contaminadas com Salmonella spp., o que também foi observado em um estabelecimento em Apodi, Lajes e Natal.

A presença de Salmonella spp. em algumas das carnes avaliadas no presente estudo, possivelmente, associa-se à contaminação durante operações de abate, processamento e embalagem.

A carne bovina in natura, fracionada ou não, pode representar um risco aos consumidores, principalmente quando a manipulação é incorreta. Quanto mais manipulada é a carne, maior é a sua susceptibilidade à contaminação (Almeida et al., 2010).

Como as carnes avaliadas no presente trabalho eram comercializadas na forma de bifes, a manipulação durante o corte pode ser um meio de contaminação, possivelmente, explicando a positividade de algumas amostras analisadas. Vale salientar que a contaminação por micro-organismos patogênicos pode ocorrer em diversas fases desde a obtenção da matériaprima, apesar da manipulação durante o corte apresentar um fator de risco a mais.

Silvestre et al. (2014) pesquisaram a presença de Salmonella spp. em carnes bovinas in natura comercializadas no município de Alexandria-RN e, de forma similar ao presente estudo, também reportaram a presença deste patógeno em algumas amostras. Estes autores verificaram que das 35 amostras analisadas, em quatro $(11,4 \%)$ foi detectada presença deste micro-organismo. Alcântara et al. (2012) detectaram presença desse patógeno em $27,77 \%$ das carnes bovinas avaliadas no seu estudo, com contagens variando de 2,08 a 4,40 $\log _{10}$ UFC/g.

Almeida et al. (2010) realizaram análises microbiológicas em carnes bovinas comercializadas em Diamantina-MG. Estes autores detectaram ausência de Salmonella spp. em bifes de coxão mole expostos a venda no município. No entanto, verificaram a presença deste patógeno em $20 \%$ das amostras de acém moído. Becker e Kiel (2011) encontraram Salmonella spp. em carnes bovinas provenientes de um dos quatro supermercados avaliados do município de Cascavel-PR.

Em contrapartida, Abreu et al. (2011) verificaram que todas as amostras de carne avaliadas, quanto à presença de Salmonella spp., no município de Umuarama-PR estavam de acordo com o padrão exigido pela Anvisa (2001), o que também foi reportado por Sousa et al. (2000) em carne bovina moída proveniente do município de Macapá-AP.

Verificaram-se elevadas contagens de Staphylococcus sp. nas amostras de bifes analisadas, com valores em UFC/g variando de $<3$ a $>7,30 \log _{10}$ UFC/g.

Segundo Germano e Germano (2008), as bactérias do gênero Staphylococcus são habitantes usuais da pele e mucosas de manipuladores, e, portanto, sua presença em níveis elevados nos alimentos sugere contaminação durante o processamento, por falta de higiene dos manipuladores.

Além disto, carnes porcionadas são mais susceptíveis à contaminação por este patógeno quando comparada às peças inteiras, o que, possivelmente, explica a elevada contaminação dos bifes detectada no presente estudo.

Apesar da legislação brasileira não estabelecer limites para a presença deste patógeno em carne bovina, vale ressaltar que a toxina estafilocócica é capaz de causar manifestações clínicas em doses inferiores a $1 \mathrm{mg}$, que é um nível de toxina alcançado quando a concentração de células ultrapassa 5 log10UFC/g (Germano e Germano, 2008).

Embora a ausência de Salmonella spp. caracterize a carne como em conformidade com a legislação brasileira, esta condição não garante a segurança da carne ao consumidor, já que Staphylococcus aureus e coliformes termotolerantes podem estar envolvidos em doenças ocasionadas pelo consumo de carne bovina (Abreu et al., 2011).

Desta forma, verificou-se no presente estudo um percentual de $55 \%$ das amostras (33 amostras) com contagens de Staphylococcus sp.superiores a $5 \log 10 \mathrm{UFC} / \mathrm{g}$, o que representa um risco à saúde do consumidor, já que em concentração elevada, pode ocorrer o aparecimento da enterotoxina em níveis críticos. Entre as amostras coletadas em Natal, apenas uma apresentou concentração de Staphylococcus sp. superior a 5 log10UFC/g, enquanto nos municípios de Pau dos Ferrros, Assu e Itaú, todos os estabelecimentos apresentaram amostras com valores superiores a 5 log10UFC/g.

Silvestre et al. (2014) detectaram Staphylococcus em todas as amostras de carne bovina in natura avaliadas do município de Alexandria-RN.

Almeida et al. (2010) verificaram que $60 \%$ e $40 \%$ das amostras de acém moído e bifes de coxão mole, respectivamente, continham elevado teor de S. aureus. Sousa et al. (2000) detectaram presença deste patógeno em $26,6 \%$ das carnes bovinas moídas coletadas em açougues no município de Macapá-AP.

A contagem de micro-organismos aeróbios mesófilos variou de 4,84 a valores superiores a $7,4 \log _{10} U F C / g$. Os psicrotróficos estavam presentes em concentrações variando de 4,32 a > 7,4 $\log _{10}$ UFC/g.

Apesar da legislação brasileira não estabelecer limites em relação às contagens de bactérias aeróbias mesófilas e psicrotróficas, estas análises são fundamentais para avaliar o estado de deterioração de carnes, principalmente em carnes cuja embalagem tem uma elevada permeabilidade ao oxigênio, entre as quais estão as avaliadas no presente estudo.

Segundo Delazari (1979), carnes cuja população de microorgansimos mesófilos supera $7 \log _{10}$ UFC/g apresentamse deterioradas, como consequência da baixa qualidade microbiológica que, por sua vez, reflete em alterações sensoriais. Verificou-se que apenas cinco (8,3\%) das 60 amostras avaliadas obtiveram concentração de mesófilos inferiores a $7 \log _{10} \mathrm{UFC} / \mathrm{g}$, ou seja, a maioria dos bifes avaliados $(91,7 \%)$ já estava com qualidade comprometida por apresentar contagens microbianas acima deste valor.

Ao contrário de micro-organismos patógenos, a presença de deteriorantes é impreterível na carne bovina. Mesmo após o abate em condição higiênica satisfatória, a carne possui aproximadamente 3 a $4 \log _{10}$ UFC/g. A minimização da contaminação no processamento e aplicação de métodos de conservação ajuda a controlar a quantidade e o crescimento desses micro-organismos (Castillo, 2006). Dessa forma, uma possível explicação para as elevadas contagens de microorganismos mesófilos e psicrotróficos reportadas no presente estudo é a falta de higiene durante a obtenção dos bifes no estabelecimento comercial ou durante a obtenção da matériaprima. Outra provável explicação é a conservação das carnes em temperaturas inadequadas ou a quebra de cadeia do frio. 
Como a carne apresenta excelentes condições para o desenvolvimento de micro-organismos, como elevado teor de nutrientes, elevada atividade de água e baixa acidez, a população de deteriorantes aumenta durante o armazenamento, mesmo em condições de refrigeração, já que os principais microorganismos envolvidos no processo de deterioração da carne são psicrotróficos (Forsythe, 2013; Jay, 2005; Ordonez, 2005).

Pigatto e Barros (2003) também detectaram elevada contaminação em carne moída, que também é uma carne muito manipulada, comercializada em açougues de Curitiba-PR.

O número mais provável (NMP) de coliformes totais e termotolerantes variou de $<2,48$ a $>5,04 \log _{10} \mathrm{NMP} / \mathrm{g}$.

A RDC - Resolução da Diretoria Colegiada - N 12 de 2001 (Anvisa, 2001) não estabelece padrões para coliformes totais e termotolerantes para bifes embalados em filmes permeáveis ao oxigênio, como os avaliados no presente estudo. Em contrapartida, a legislação estabelece limite de $10 \mathrm{NMP} / \mathrm{g}$ para coliformes a $45^{\circ} \mathrm{C}$ para carnes bovinas embaladas a vácuo. Ao observar os resultados dos bifes analisados, verifica-se que apenas $19(31,7 \%)$ se enquadrariam nos padrões para carnes embaladas a vácuo, enquanto $41(68,3 \%)$ amostras superariam os limites supracitados.

Como os coliformes são micro-organismos indicadores (Franco e Landgraff, 2008), o elevado NMP de coliformes detectado no presente estudo pode estar associado às condições higiênicosanitárias inadequadas durante a obtenção da matéria-prima ou processamento. Como as carnes avaliadas no presente estudo eram fracionadas, o corte dos bifes representa um fator de risco de contaminação por coliformes adicional.

Silva et al. (2004) verificaram uma condição sanitária insatisfatória na carne moída comercializada em João PessoaPB. Estes autores detectaram que todas as amostras avaliadas estavam contaminadas por coliformes totais e termotolerantes em um nível de $3 \log _{10} \mathrm{NMP} / \mathrm{g}$, caracterizando este tipo de alimento como um potencial causador de doenças alimentares.

Oliveira et al. (2008) pesquisaram coliformes totais, coliformes termotolerantes e Staphylococcus aureus nas mãos de manipuladores de carne bovina moída, encontrando uma elevada contaminação, destacando as mãos dos manipuladores como uma importante via de contaminação de carnes bovinas.

\section{Referências}

ABREU, C.O.; MERLINI, L.S.; BEGOTTI, I.L. Pesquisa de salmonella spp, staphilococcus aureus, coliformes totais e coliformes termotolerantes em carne moída comercializada no município de Umuarama - PR* . Arquivos de Ciências Veterinárias e Zoologia da UNIPAR, Umuarama, v. 14, n. 1, p. 19-23, 2011.

ALCÂNTARA, M. A.; GATTO, I. R. H.; KOZUSNY-ANDREANI, D. I. Ocorrência e perfil de suscetibilidade aos anticrobianos de micro-organismos isolados de cortes de carne bovina. Veterinária em Foco, v. 10, n. 1, 2012.

ALMEIDA, A.C.; SOUZA, R.M.; PINHO, L.; SOBRINHO, E.M.; SILVA, B.C.M. Determinação de perigos microbiológicos em carnes bovinas resfriadas provenientes de abates clandestinos e comércio ilegal. Acta Veterinária Brasílica, v. 4, n. 4, p. 278-285, 2010.
Leite Júnior et al. (2013) reforçam que elevadas contagens de micro-organismos indicadores, tais como os coliformes, é indicativo de ocorrência micro-organismos de origem fecal, provável presença de patógenos, deterioração potencial do alimento, bem como más condições sanitárias durante o processamento, produção ou estocagem.

Silvestre et al. (2014) detectaram coliformes termotolerantes em $100 \%$ das carnes bovinas in natura analisadas, coletadas no município de Alexandria-RN. Estes autores encontraram médias elevadas de coliformes termotolerantes tanto em carnes provenientes de açougues como de supermercados, iguais a 4,08 e 3,09 log NMP/g, respectivamente.

Xavier e Joele (2004) também encontraram coliformes a $45^{\circ} \mathrm{C}$ em todas as amostras de carnes analisadas coletadas na cidade de Belém-PA. Lundgren et al. (2009) detectaram coliformes termotolerantes em $100 \%$ das carnes avaliadas de feiras livre e mercados públicos de João Pessoa-PB. Estes autores encontraram NMP de coliformes totais variando de 2,38 a >3,38 $\log _{10} \mathrm{NMP} / \mathrm{g}$, enquanto que o NMP de termotolerantes variou de 1,96 e $>3,38 \log _{10} \mathrm{NMP} / \mathrm{g}$.

Quanto aos valores de $\mathrm{pH}, 96,7 \%$ das amostras estavam em conformidade com a legislação brasileira para este parâmetro. $\mathrm{O}$ pH de 6,4 é o limite crítico para o consumo de carnes (Brasil, 1997). A partir dos dados de $\mathrm{pH}$ encontrados no presente estudo, verifica-se que esta análise realizada de forma individual não é confiável para indicar o nível de deterioração das carnes, pois apesar da maioria das amostras terem apresentado elevado nível de contaminação por micro-organismos mesófilos e psicrotróficos, apenas duas amostras apresentaram $\mathrm{pH}$ acima de 6,4.

\section{Conclusões}

Os bifes de carne bovina coletados em estabelecimentos localizados Rio Grande do Norte apresentaram baixa qualidade microbiológica nos parâmetros estudados.

A análise de $\mathrm{pH}$ não é um parâmetro confiável para indicar o nível de deterioração das carnes, pois apesar da maioria das amostras ter apresentado elevado nível de contaminação por micro-organismos mesófilos e psicrotróficos, apenas duas amostras apresentaram $\mathrm{pH}$ acima do limite preconizado pela legislação.

ANVISA. Agência Nacional de Vigilância Sanitária. Resolução RDC $n^{\circ} 12$, de 02/01/2001. Regulamento Técnico sobre padrões microbiológicos para alimentos. Diário Oficial da República Federativa do Brasil, Brasília, DF, 10 jan. 2001, Seção I, p. 45-53.

BECKER, A.K.; KIEL, G..Análise microbiológica de carne bovina in natura comercializada em supermercados de Cascavel-PR. Revista Thêma et Scientia-Vol, v. 1, n. 2, p. 149, 2011.

BRASIL. Ministério da Agricultura, Pecuária e Abastecimento. Instrução Normativa $N^{\circ} 62$, de 26 de agosto de 2003. Oficializa os métodos analíticos oficiais para análises microbiológicas para controle de produtos de origem animal e água. Diário Oficial do Brasil, Brasília, DF, 26 ago. 2003. Seção I. p. 14.

BRASIL. Ministério da Agricultura, Pecuária e Abastecimento. Regulamento da inspeção industrial e sanitária de produtos de origem animal. Brasília: Ministério da Agricultura, Pecuária e Abastecimento, 1997. 
CASTILO, C.J.C. Qualidade da carne. São Paulo: Varela, 2006. $240 \mathrm{p}$.

DELAZARI, I. Microbiologia de carnes - microrganismos causadores de deterioração da carne e produtos cárneos. Boletim da Sociedade Brasileira de Ciência e Tecnologia de Alimentos, v. 49, p. 3-39, 1979.

FORSYTHE, S.J. Microbiologia da segurança dos alimentos. 2. ed. São Paulo: Artmed, 2013, 607 p.

FRANCO, B.D.G.; LANDGRAF, M.. Microbiologia dos alimentos. São Paulo: Atheneu, 2008.

GERMANO, P.M.L.; GERMANO, P.M.L. Higiene e vigilância sanitária de alimentos. 3. ed. São Paulo:Manole, 2008, 986 p.

INSTITUTO ADOLFO LUTZ. Métodosfísico-químicos para análise de alimentos. São Paulo: Intituto Adolfo Lutz,2008. 1020 p.

JAY, J. Microbiologia de Alimentos. 6. ed. São Paulo: Artmed. 2005, 2011 p.

LEITE JÚNIOR, B.R.C. Qualidade microbiológica de alimentos de origem animal comercializados na região de Minas Gerais. Vértices, v. 15, n. 2, p. 49-59, 2013.

LUNDGREN, P.U.; SILVA, J.D.; MACIEL, J F.; FERNANDES, T.M. Perfil da qualidade higiênico-sanitária da carne bovina comercializada em feiras livres e mercados públicos de João Pessoa/PB-Brasil. Alimentos e Nutrição, v. 20, n. 1, p. 113-119, 2009.

MOTTA, M.R.A.; BELMONTE, M.A.; PANETTA, J.C. Avaliaçäo microbiológica de amostras de carne moída comercializada em supermercados da região oeste de Säo Paulo. Higiene Alimentar, v. 14 , n. $78 / 79$, p. $59-62,2000$.
OLIVEIRA, M.M.M.; BRUGNERA, D.F.; MENDONCA, A.T.; PICCOLI, R.H. Condições higiênico-sanitárias de máquinas de moer carne, mãos de manipuladores e qualidade microbiológica da carne moída. Ciência e Agrotecnologia, v. 32, n. 6, p. 18931898, 2008.

ORDÓÑEZ, J.A. Tecnologia de Alimentos de Origem Animal. v. 2. São Paulo: Artmed, 2005. 279 p.

PIGATTO, C.P.; BARROS, A.R. Qualidade da carne moída bovina resfriada, comercializada em açougues da região de Curitiba. Higiene Alimentar, v. 17, n. 108, p. 53-57, 2003.

RAMOS, E.M.; GOMIDE, L.A.M. Avaliação da qualidade de carnes: fundamentos e metodologias. Viçosa: Editora UFV, 2012, $599 \mathrm{p}$.

SANTOS, J.S.; OLIVEIRA, M.B.P.P. Alimentos frescos minimamente processados embalados em atmosfera modificada. Brasilian Journal of Food Technology, v. 15, n. 1, p. 1-14, 2012.

SILVESTRE, M.K.; ABRANTES, M.R.; PAIVA, W.S.; SOUZA, Ê.S.; SILVA, J.B. A. Avaliação da qualidade da carne bovina in natura comercializada no município de alexandria-RN. Acta Veterinaria Brasilica, v. 7, n. 4, p. 327-331, 2014.

SOUSA, C.L.; JOELLE, M.R.S.P.; SILVA, E.D.C.; DE OLIVEIRA, R.I.S. Avaliação da qualidade microbiológica e físico-química da carne bovina moída em açougues do Município de Macapá-AP. Higiene Alimentar, v. 14, n. 72, p. 60-65, 2000.

SILVA, C.A; SOUSA, E.L.; SOUSA, C.P. Estudo da qualidade sanitária da carne moída comercializada na cidade de João Pessoa, PB. Higiene alimentar, v. 18, n. 121, p. 90-94, 2004.

XAVIER, V.G.; JOELE, M.R.S.P. Avaliação das condições higiênico-sanitárias da carne bovina in natura comercializada na cidade de Belém, PA. Higiene alimentar, v. 18, n. 125, p. 64-73, 2004. 